\title{
Possible Selves and Academic Outcomes: How and When Possible Selves Impel Action
}

\author{
Daphna Oyserman, Deborah Bybee, and Kathy Terry \\ The University of Michigan
}

\begin{abstract}
Puzzled by the gap between academic attainment and academic possible selves (APSs) among lowincome and minority teens, the authors hypothesized that APSs alone are not enough unless linked with plausible strategies, made to feel like "true" selves and connected with social identity. A brief intervention to link APSs with strategies, create a context in which social and personal identities felt congruent, and change the meaning associated with difficulty in pursuing APSs $(n=141$ experimental, $n=123$ control low-income 8th graders) increased success in moving toward APS goals: academic initiative, standardized test scores, and grades improved; and depression, absences, and in-school misbehavior declined. Effects were sustained over a 2-year follow-up and were mediated by change in possible selves.
\end{abstract}

Keywords: possible selves, African American, Hispanic, prevention, self-regulation

From early adolescence, the future is an important component of self-concept (McGuire \& Padawe-Singer, 1976), and doing well in school is a common element of youths' future-oriented selves (Oyserman, Johnson, \& Bybee, 2006). These future or possible selves (PSs) are positive and negative images of the self already in a future state - the "clever" self who passed the algebra test, the "fat" self who failed to lose weight, the "fast" self who fell in with the "wrong" crowd (Oyserman \& Markus, 1990). A number of self-regulatory models have posited positive and negative consequences of PS-PS motivate current action (Baumeister, 1998; Carver \& Scheier, 1990; Eccles \& Wigfield, 2002; Higgins, 1996a; Oyserman \& Markus, 1990; Weinstein, 1993). Failure to attain PSs (Oyserman \& Fryberg, 2006), hoped for selves, or ideal selves (Strauman, 2002; Strauman \& Higgins, 1988) may increase risk of depression. There is some evidence that imagining successful PSs improves well-being (King, 2001) and performance (Ruvolo \& Markus, 1992). However, PSs do not always sustain selfregulatory action. Youth fail algebra, fall off weight maintenance, and engage in risky behavior, perhaps also increasing their risk of feeling depressed at their inability to move toward their self-goals.

Why might PSs fail to sustain self-regulatory action? Given that the self is multidimensional and includes multiple potentially competing goals (e.g., Abrams, 1994; Burke, 2003; King \& Smith, 2004; Oyserman, 2001; Settles, 2004), a particular PS may fail to sustain self-regulatory action because it conflicts with other parts

Daphna Oyserman, Deborah Bybee, and Kathy Terry, The Institute for Social Research, The University of Michigan.

This work was supported by National Institute of Mental Health Grant R01 MH 58299. We thank the students, parents, trainers, teachers, school staff, and community members involved in the intervention, data collection, and tracking; Jim Klein for help in obtaining school data; and our coordinating and database managers, Carol Carlin, Johnessa Dimicks, Tami Hart-Johnson, and Angelique Lange.

Correspondence concerning this article should be addressed to Daphna Oyserman, The Institute for Social Research, The University of Michigan, Ann Arbor, MI 48106-1248. E-mail: daphna.oyserman@umich.edu of self-concept. Another possibility is that PSs fail to sustain self-regulatory action because sustaining self-regulatory effort over time is difficult, and youth may misinterpret difficulty as evidence that the PS is not a reasonable goal and should be abandoned. To predict when a particular PS is likely to motivate action, is it necessary to have a model that predicts which PSs are likely to be online in working memory and, of these PSs, which will be invested in over time.

In the current paper, we focus on school-related PSs and outline and test a predictive model. We propose that youth have difficulty creating and sustaining school-focused PSs when they perceive these PSs to be incongruent with important social identities (e.g., racial-ethnic identities), misinterpret difficulties in working on these PSs as evidence that academic goals are unrealistic PSs, and live in social contexts that fail to cue strategies for attaining their PS goal. Youth will commit sustained self-regulatory effort to a PS when the PS itself is effective and contains behavioral strategies and social context supports working on the PS, when the PS feels congruent with important social identities, and when difficulty working on the PS is construed as normative. In the following sections, we outline each of these links and the intervention we developed based on this model with a goal of enhancing the self-regulatory impact of PS.

\section{PSs and Self-Regulatory Behavior}

\section{Effective PSs}

A number of studies suggest that PSs differ in self-regulatory effectiveness. Self-regulatory effort improves when youth have both positive PSs (goals) and negative PSs (fears) in the same domain ("balanced" PSs) (Oyserman \& Markus, 1990) and when youth have incorporated detailed strategies into their PSs ("plausible" PSs) (Oyserman, Bybee, Terry, \& Hart-Johnson, 2004). When PSs are balanced, individuals select strategies that both increase the likelihood of becoming like the positive PSs and decrease the likelihood of becoming like the negative PSs, thereby focusing self-regulation and broadening effort (Oyserman \& 
Markus, 1990). Plausibility provides automatic cuing of predeveloped strategies (e.g., "set my alarm," "go to class even if my friends skip"); indeed, youth with plausible academic PSs (APSs) are able to improve their grades over the course of the school year, whereas those who simply had APSs are not (Oyserman et al., 2004). Despite the fact that most low-income youth have at least one PS focused on school, few of these PSs include strategies (Oyserman et al., 2006). Many youths fail to attain even the basic academic PS goal of graduating high school. Thus, the national average for on-time graduation is $75 \%$ overall, $50 \%$ for African Americans, and 53\% for Hispanics) (Orfield, Losen, Wald, \& Swanson, 2004). In urban centers like Detroit, graduation estimates are even lower (between $40 \%$ and $44 \%$ on-time graduation) (Detroit News, 2005).

\section{Contextual Cuing of PSs}

Not only is the potential self-regulatory impact of having a PS goal undermined when PSs are not balanced or plausible, selfregulatory effectiveness is also undermined when social contexts do not cue the PS. Because information that is cued (chronically or situationally made salient) is likely to be used in judgments and decision-making (Higgins, 1996b), contextually cued PSs should influence self-regulatory behavior more than those that are not cued. Moreover, to sustain ongoing engagement in school, PSs must be linked with behavioral strategies; positive expected APSs need to be linked with strategies to attain them, and feared APSs need to be linked with strategies to avoid them.

Although resource-rich contexts such as a middle-class neighborhood and school provide models of success and a developed structure to guide the process of attaining APSs, this is unlikely to be the case in resource-limited contexts. In middle-class contexts, strategies may be automatically cued; parents, teachers, and parents of friends all converge to emphasize homework, persistence in the face of difficulty, tutoring, or staying after school if needed. In low-socioeconomic status (SES) contexts, strategies are unlikely to be automatically cued because these contexts are less likely to present easily accessible models or to guide success (e.g., Roderick, 2003). In low-SES contexts, youth encounter adults who are likely to be unemployed, have low academic attainment, and hold nonprofessional jobs. Given lack of easily accessible models or automatically cued strategies, youth may maintain an abstract commitment to education without connecting these PSs to everyday behavior, expressing high aspirations even as their behavior reflects avoidance or even flight from school (for qualitative description, see Roderick, 2003).

\section{APSs and Social Identities}

Self-concepts include both personal and social identities. Social identities are aspects of self-concept based not in individual traits and goals but on group-based traits and goals (Oyserman, in press). It seems reasonable that social identities will incorporate community expectations about the occupations and academic attainment of in-group members. Minority youth living in low-SES contexts are exposed to images of the in-group as low achieving (Thomas, Townsend, \& Belgrave, 2003), raising the possibility that the selves possible for in-group members may not feel congruent with APSs.
The negative link youths perceive between minority status and academic attainment and eventual occupation can be seen both in ethnographic descriptions and in experimental paradigms. Ethnographic research suggests that high school students perceive Latinos as more likely to become manual laborers, Asians to do well in school, and African Americans to do poorly in school (Kao, 2000). The same results emerge from scenario-based experimental research, whether focused on the link between minority status and low academic attainment or on the link between low social class and low academic attainment. Thus, when a failing student is described, Latino and African American students are more likely to predict that the target is Latino or African American than White (Graham, 2001). When asked to predict academic performance of a target student, low-income students infer worse performance from low (vs. middle) social class peers (Régner, Huguet, \& Monteil, 2002; Weinger, 2000).

When imagining what future is possible for one's self, such negative preformed group images are likely to be highly accessible, making social group membership feel like it conflicts with APSs. Working toward one's APS is likely to feel harder in the presence of accessible images of in-group members engaging in behaviors that undermine chances of attaining APSs and failing to engage in behaviors that would help attain APSs. Although there is debate as to the degree of evidence that school success is viewed as a White middle-class goal (Cook \& Ludwig, 1997; Ferguson, 1998), there is consistent evidence of the stereotyped link between minority status and low achievement (e.g., Steele, 1997).

The stereotype threat literature documents that simply bringing to mind category membership as minority or working class dampens academic performance (e.g., Croizet \& Claire, 1998; Steele, 1997). Individuation or separation of self from in-group alleviates this effect (Ambady, Paik, Steele, Owen-Smith, \& Mitchell, 2004), but the idea of intervening to disconnect youth from their racialethnic in-group (e.g., creating "racelessness"; see Fordham \& Ogbu, 1986) is unappealing and likely to have other negative consequences (Arroyo \& Zigler, 1995). Thus, rather than attempting to dampen the centrality of important social identities as a way to improve success in attaining APSs, increasing felt congruence between APSs and social identity, is a more reasonable strategy.

\section{APSs and Inoculation From Overinterpretation of Difficulty}

In addition to the linkage of the APS to self-regulatory behavior and integration with important social identities, taking into account research on how salient information influences judgment and behavior may close what appears to be a puzzling gap between the high value placed on education and the actual attainment of lowincome and minority youth. Working on one's APS is likely to be difficult. To judge what this difficulty means, whether APSs are "true" PSs or contradict other important social identities, to judge whether attaining these PSs is plausible or not worth the effort, teens must answer the implied questions "Why is engaging in this APS so hard for me; is this really the true me? Do we have PSs like this?" Likewise, they must judge whether particular behavioral patterns (e.g., asking for help) are likely to work and if they contradict in-group identity (e.g., "Will asking the teacher for help actually help me succeed in school or is it just a 'White' thing to do?'). 
To better understand how the feelings of difficulty that are experienced as adolescents imagine and pursue their PS influence commitment to that PS, it is fruitful to reconsider James' (1890) original formulation of the self. James viewed the self as comprised both of content-what one thinks about when one thinks about one's self and the accompanying metacognitive processthe feeling of thinking about one's self. This implies that selfjudgments about who one is or may become are based on both content (what comes to mind) and process. Considering the content of thoughts about the self separately from the feelings associated with these thoughts parallels work in social cognition (Schwarz, 1998, 2002). This work proposes that human reasoning is accompanied by metacognitive experiences of relative ease (difficulty) and fluency (disfluency) (Schwarz, 1998, 2002).

Following from this research in social cognition, when imagining a PS is accompanied by a metacognitive experience of difficulty, the feeling of difficulty is interpreted with a naïve theorythings that are hard to think of are less likely to be true (Higgins, 1998; Schwarz \& Bless, 1992; Schwarz \& Clore, 1996). The experience of ease or difficulty when bringing to mind a PS can provide the basis for inferring whether a PS is a "true" self that is worth pursuing and investing effort in or a "false" self, conflicting with social identities. Metacognitive experience of ease also provides feedback as to whether the gap between the current and PS is manageable or unmanageable and therefore whether the PS should be expanded or abandoned.

Although the experience of metacognitive difficulty is generally interpreted as meaning "not true for me," a number of studies have documented that other interpretations are possible (Rothman \& Schwarz, 1998). Sports stories abound with reinterpretation of the meaning of experienced difficulty (e.g., "no pain, no gain") and the need to keep trying (e.g., "you miss $100 \%$ of the shots you don't take"). In the case of attempting to attain APS, although the metacognitive experience of difficulty is generally interpreted as "not the true me," the experience of difficulty could be reinterpreted to mean other things. Difficulty can be viewed as a norma- tive part of the process (e.g., "success is 1\% inspiration and $99 \%$ perspiration"). Difficulty can also provide evidence of progress (e.g., "the important things in life are the ones you really have to work for"); if difficulty and failures along the way are viewed as critical to eventual success, then difficulty is evidence of striving.

Successful movement toward positive APSs and away from feared APSs requires ongoing behavior; it is not enough to complete one homework assignment or stay after class one day. If one's metacognitive experience is that working on a PS is difficult and if this difficulty is interpreted with a naïve theory that ease is associated with truth, then difficulties associated with working toward the PS will undermine it. As we have outlined, low-income and minority youth are likely to experience at least three sources of difficulty - difficulty bringing to mind APSs and linking them to strategies, difficulty sustaining the behavioral self-regulation PS strategies entail, and difficulty integrating APSs and social identities.

Youth growing up in low-SES contexts have multiple models of adults who failed to attain their PSs, making it unlikely that they will recognize the normativeness of difficulties and instead likely that they will misinterpret feelings of difficulty as a sign of inevitable failure. This misinterpretation is crucial because it is likely to undermine behavioral persistence in pursuit of PS goals. Thus, rather than assuming that youth are able to make sense of difficulty as normative, low-SES youth are likely to need specific inoculation from overinterpreting current difficulty and failure as predictive of future possibilities. Taken together, their metacognitive experience of difficulty is likely to provide feedback that APSs are false rather than true selves, cuing disengagement from these PSs and the goal pursuit they imply.

\section{PSs: A Process Model and Proposed Intervention}

Figure 1 presents our process model of the connections among PSs, self-regulatory behaviors, academic outcomes, and mental health. The process model links social identities and metacognitive

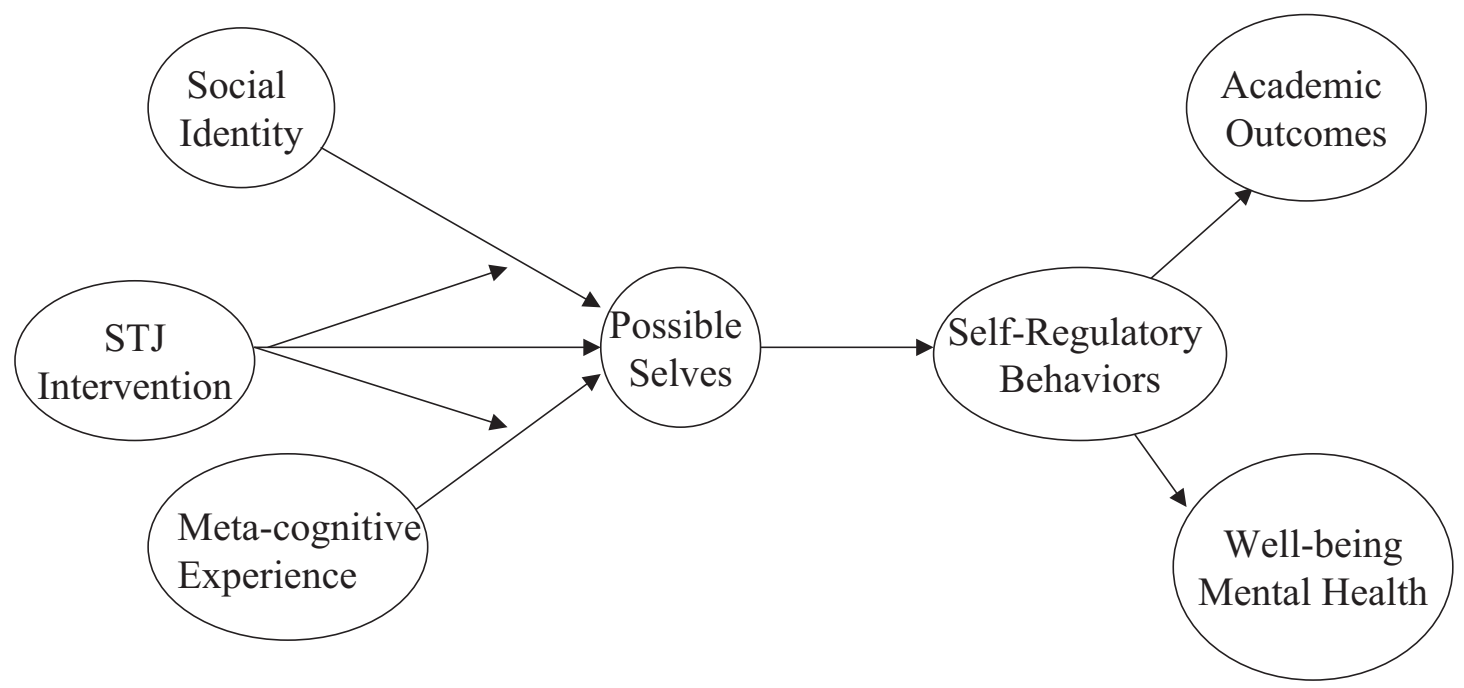

Figure 1. Process model. Theorized effects of the STJ intervention on PSs and of PSs on academic engagement, academic outcomes, and depression. 
experience to PSs and links PSs to persistent engagement in self-regulatory behavior. To test this model, we developed an intervention (labeled STJ in Figure 1). The goals of the intervention were to evoke PSs and strategies to attain them, forge links between PSs and strategies that are not otherwise automatic, inoculate youth from misinterpreting failure and setbacks in attaining these PSs, and create a link between social identity and PSs.

Ease is typically the basis for metacognitive judgment, so we took care to ensure that sessions felt easy, so that students would not immediately develop a metacognitive sense that thinking of the future is hard and therefore "not for me." We based the intervention in school so that strategies articulated in the intervention would be cued in school. We structured intervention activities to make APSs salient, create linking connections between APSs and strategies, make salient naïve theories of the meaning of difficulty that link difficulty with progress toward meaningful goals, and create a space in which APSs and social identity are congruent.

Together, these activities were designed to "inoculate" youth from withdrawing effort to attain positive APSs and avoid feared APSs. In the long term, this change in PSs was expected to evoke persistent change in self-regulatory behavior. That is, we expected that behavior relevant to APSs (e.g., doing homework) would increase and that behavior undermining APSs (e.g., misbehaving in class) would decrease. Over time, sustained self-regulatory behavior should produce better academic outcomes, that is, grade point average (GPA). Moreover, because sustained self-regulatory behavior should reduce discrepancy between current and future selves, intervention youth should have the added benefit of reduced risk of depression (Higgins, 1997) and other mental health problems.

Session 1 focused on making APSs salient and relevant as well as relevant to social identity: Each group member introduced a partner in terms of the skills or ability the partner possessed that would help him or her complete the school year successfully (e.g., "well-organized," "positive attitude"). This provided an initial example of APSs and social identity as congruent; because all youth engaged in the task, the metamessage was "we all care about school." Session 2 focused on adult PSs: Youth picked photographs that fit their adult "visions" (PSs). Because most adult PSs youth describe are images of material success, the metamessage was "we all want a good future." Because all youth choose photographs of adult PSs, successful PSs and social identity are presented as congruent.

In Session 3, students drew role models and negative forcespeople or things that provide energy to work toward PSs and those that are draining or nay-saying. The metamessage was "everyone faces obstacles and difficulties; this does not make the PSs less part of the 'true' self." In Session 4, students drew timelines into the future, including forks in the road and obstacles. The metamessage was "everyone has difficulties, and failures and setbacks are a normal part of timelines and do not mean that APSs are not true selves."

Session 5 introduced action goals, allowing students to practice articulating specific strategies to attain their APSs, further highlighting the normativeness of difficulty in attaining APSs. Sessions 6 and 7 focused on PSs and strategies to attain them, building on previous sessions, with a different concrete medium, poster board, stickers, and markers. Students chose next year feared and to-beexpected PSs and linked them with current and possible strategies.
Sessions 8 to 10 focused on decoupling difficulty and genuineness explicitly through work in smaller groups on everyday problems, social problems, academic problems, and the process of getting to high school graduation, and the metatheme was that all students care about these issues, that difficulties are normative and not self-defining. Session 11 cemented the new metacognitive interpretations by having participants review and critique the sessions. Two follow-up sessions included parent/guardians and community members, with the goal of helping youth broker their APSs in the community outside of school in ways that link APSs with social identities.

\section{Hypotheses}

Two key hypotheses follow from our model. (a) The intervention will directly influence PSs, self-regulatory behaviors, academic outcomes, and risk of depression. (b) Effects of the intervention on self-regulatory behaviors, academic outcomes, and depression will be mediated by intervention effects on PSs. That is, shift in PSs will improve engagement in self-regulatory behaviors, and engagement in self-regulatory behaviors will increase academic success and reduce feelings of depression. We also hypothesized (c) that the intervention would influence the relationship between APSs and social identity, creating conditions for APSs and social identity to feel congruent. To test these hypotheses, we examined the direct effects of the intervention on change in PSs and the longitudinal effects of the intervention, both direct and as mediated by PSs. Finally, we examined the long-term effects of the intervention on the relationship between APSs and social identity as operationalized by racial-ethnic identity.

\section{Method}

\section{Sample}

Data were collected at three Detroit middle schools; $71.6 \%$ of students were African American, $17.4 \%$ were Latino, and $11.0 \%$ were White; total $N$ for analyses $=264$ as detailed below. Students were low-income, as evidenced by school lunch program (two-thirds received free or reduced lunch), neighborhood (in the students' census tracts, $n=105,54.1 \%$ of households were below the poverty line and only $43.4 \%$ of adults were employed; U.S. Bureau of Census, 2000), housing stability (45.2\% moved at least once over the 2 years we tracked them; those who moved averaged 1.54 moves), and school stability (20\% changed schools during the 1 st year).

\section{Procedure}

Obtaining permission. School district and school principals approved random assignment and provision of the intervention during the elective hour. School-based data collection in low-income and minority populations typically is hampered by low consent rates (Ellickson \& Hawes, 1989). Parents who are lower income and have more academically at-risk students are less likely to return consent forms, reducing generalizability of findings (Kearney, Hopkins, Mauss, \& Weisheit, 1983; Pokorny, Jason, Schoeny, Townsend, \& Curie, 2001). Because not returning a consent form mailed home (the standard protocol) is not the same as refusing participation when asked directly, these authors argue for passive rather than signed consent to protect generalizability of findings. We also obtained the typical low response rate with the standard mailing procedure (15\% return rate). Rather than limit generalizability, we followed up the $85 \%$ nonresponders with personal contact (by phone if they had one or by going to the home) to 
explain the study and what we would do with the data and to ask for permission or refusal. Together, the initial mailing and direct communication were well received, resulting in a total signed consent rate of $94.3 \%$ and no differences by race/ethnicity or condition.

Data collection. Core subject teachers (blind to experimental assignment) assessed student in-class behavior. Test scores, GPA, and attendance were obtained from school records. Student surveys were administered in-class. Teacher and student baseline data collection occurred prior to the intervention. Teacher and student postintervention data were collected at three additional times, at the end of the 8th grade school year and again in the fall and spring of the following year. School records were obtained each time report cards were issued over the 2-year data collection period (1st quarter of 8th grade through the end of 9th grade). Because the intervention occurred prior to 1st quarter 8th grade grades, the youth baseline survey included self-report of grades to provide a prior academic attainment control variable. Teachers were not present for student surveys to assure confidentiality. Instructions were read aloud, and research staff circulated to assist students. In-home interviews were completed in year 1 for the 56 students suspended $(n=11)$, expelled $(n=9)$, transferred $(n=10)$, or otherwise not in school $(n=26)$. By year 2 , students were enrolled in 80 schools; the at-home interview procedure was followed when in-school survey completion was not feasible. Teachers were reimbursed $\$ 5$ for each assessment (\$10 in year 2); students were reimbursed \$5 (year 2 only).

Missing data. Extensive tracking efforts minimized data loss. We obtained data from at least one source across all four semesters of data collection for a full $96 \%$ of our sample, $89.8 \%$ to $97.3 \%$ of student, $92.4 \%$ to $95.8 \%$ of school records, and $83.3 \%$ to $96.6 \%$ of teacher ratings. All but 4 youth had data from at least one source at semester 4 . To preserve generalizability, expectation maximization methods were used to estimate the approximately $7.9 \%$ of the data matrix that were missing due to skipped items or unavailable information. Although missingness was not completely random, Little's missing completely at random $\chi^{2}(d f=16,115)=$ $30,685.46, p<.001$, there was no evidence that it was not ignorable (Little \& Rubin, 2002). All results reported use estimated data.

Experimental manipulation. In each homeroom, approximately onehalf of students were randomly assigned to attend the regular elective period (control group), and one-half were assigned to attend the intervention as the elective period (experimental group). We called the intervention School-to-Jobs (STJ) and the overall project Pathways for Youth to prevent any potential stigmatization. Students who enrolled in school late $(n=3)$ or had an elective period broken by lunch $(n=34)$ were not randomized, resulting in an effective cohort of 280. Analyses involve the 264 students with signed parental consent ( $n=141$ experimental, $n=123$ control; $n=$ 140 female; $n=191$ African American, $n=45$ Latino, $n=28$ White). The STJ intervention thumbnail sketched in the introduction is fully manualized and includes a detailed fidelity assessment protocol (both available from the first author). STJ was provided twice weekly over a 7-week period (due to elective periods missed for school half days) with the two supplemental parent-youth STJ sessions provided the following evenings or weekend. Groups averaged 12 participants. Of youth in school, attendance was $80 \%$ to $90 \%$ for the youth in-school sessions, and $40 \%$ attended at least one parent-youth supplemental session. Two trainers ran each group. Fidelity to protocol was maintained via in vivo rating and weekly staff meetings. Trainers and observers were female Detroiters with previous experience who received intensive structured training in the protocol (for trainers, 39.5 hours; for observers, 69.5 hours).

Verification of random assignment. Randomization was successful. Comparison of the experimental and control groups on the 13 baseline measures showed no significant differences on the multivariate, $F(13$, $250)=1.07, p=.39$, or on any of the univariate $F \mathrm{~s}$.

\section{Measures}

Demographics. Schools provided gender and birthdates; youths provided their race/ethnic description.
PSs. PSs were assessed in 8th grade and spring of 9th grade using the standard open-ended format (available at http://www.sitemaker.umich.edu/ culture.self/files/possible_selves_measure.doc, 07-22-2003, Oyserman \& Saltz, 1993; Oyserman, Terry, \& Bybee, 2002). Youth generated expected PSs, noted strategies to attain each PS, and repeated this process for feared PSs. PSs were content coded following Oyserman and Markus (1990) by five coders with access only to PS responses. All PSs were double coded, and interrater reliability was $94 \%$ (disagreements discussed to agreement) Analyses focused on the two most commonly generated PSs, academic PSs and feared off-track PSs. At baseline, $96.6 \%$ of youth generated an expected APS, $63.6 \%$ generated a feared APS, and $51.1 \%$ generated a feared off-track PSs.

Feared off-track PSs. These PSs focused on involvement in gangs or violence (30\% of responses), drugs $(30 \%)$, delinquency or involvement with the police (30\%), and becoming pregnant and other "status" offenses (10\%), fall 8th grade, $M=0.74, S D=.90$; spring 8th grade, $M=.85$, $S D=.83$; spring 9th grade, $M=1.41, S D=1.04$. Raw counts were skewed so they were transformed into change scores (spring-fall), improving distribution and focusing on the impact of the intervention on change in PSs during 8th grade; change scores are appropriate when groups are randomly assigned and variances similar across observations (Cribbie \& Jamieson, 2000; Maris, 1998). Change in feared off-track PSs ranged from -3 to $+3, M=0.11, S D=1.04$.

APS balance. Balance (the number of pairs of expected and feared APSs, e.g., expecting to "pass the 8th grade" while wanting to avoid "failing and having to be an 8th grader again") was coded following Oyserman and Markus (1990). About one-third of youth had at least one balanced APS pair, fall 8th grade, $M=0.39, S D=.56$; spring 8th grade, $M=.40, S D=.57$; spring 9 th grade, $M=.30, S D=.59$. Raw counts were skewed so they were transformed into change scores (spring-fall), improving distribution, and focusing on the impact of the intervention on change in PSs during 8th grade; change in APS balance ranged from -2 to +3 , $M=0.01, S D=0.69$. For moderated regression analysis (Hypothesis 3), 9th grade APS balance scores were log-transformed (raw spring 9th grade scores had skew of 2.5 and kurtosis of 8.47), reducing skew and kurtosis to $<1.5$.

APS plausibility. The set of expected and feared APSs and strategies was coded using a 6 -point scale $(0=n o$ APSs to $5=$ at least 4 APSs and APS strategies) (Oyserman et al., 2004). Youth averaged about two APSs and strategies, fall 8th grade, $M=2.26, S D=1.30$; spring 8th grade, $M=$ $2.08, S D=1.25$; spring 9 th grade, $M=2.18, S D=1.26$. APS plausibility was not skewed, so log-transformation was not necessary, and intervention effects were assessed by examining plausibility in spring 8th grade. The coding manual and detailed instructions are found on http://sitemaker .umich.edu/daphna.oyserman/files/plausibility_instructions_only012903.doc.

\section{Social Identity}

Social identity was operationalized with a 4-item, 5-point Likert response $(1=$ strongly disagree, $5=$ strongly agree $)$ in-group connectedness scale, spring 9th grade, $M=4.18, S D=.59, \alpha=.76$. Students filled in their main racial-ethnic group and then responded. For the group "African American," example items are "I feel close to African Americans," "It is important to me to think of myself as an African American," and "I feel a part of the African American community." Analysis of connectedness to racial-ethnic in-group excluded the $n=28$ White students because "White identity" is unlikely to have the same meaning as minority racial-ethnic identity.

\section{Self-Regulatory Behavior}

Time spent doing homework. In 8th grade, we asked "How many hours a week do you usually spend doing homework?" Open ended responses ranged from 0 to 20 hours and were log-transformed to reduce skew. On an 
8-point closed ended follow-up question ( $0=$ no time to $7=$ more than 10 hours $)$, fall $M=3.89(S D=1.77)$ and spring $M=3.89(S D=1.95)$, mean responses reflected about 2 hours a week. In 9th grade, we used a 1-week event history calendar (Belli, 1998); again, students reported about 2 hours of weekly homework, fall $M=160.20$ minutes, $S D=151.89$; spring $M=$ 112.15 minutes, $S D=111.28$. Homework time was low; as a benchmark, national daily diary report data for 12 to 14 year olds are 4.40 hours weekly (Juster, Ono, \& Stafford, 2004).

Disruptive behavior. Eighth grade youth reported "How often does the teacher make you leave the classroom because of your behavior?" on a 7 -point scale $(1=$ never, $2=$ once or twice a year, $3=$ less than once a month, $4=$ once a month or so, $5=$ once every few weeks, $6=$ once $a$ week or so, $7=$ more than once $a$ week), fall $M=2.18, S D=1.55$; spring $M=2.64, S D=1.94$. Teachers reported on youth behavior with a 4-item 5-point response $(1=$ never, $5=$ always $)$ (Finn Disruptive Behavior Scale, Finn, Pannozzo, \& Voelk1, 1995; 8th grade revision, J. Finn, personal communication, October 14,1998 ) scale each semester, $\alpha=79, .81, .78$, and .80 , respectively. Beginning with the stem "This student ...," items were "annoys peers or interferes with peers' work," "is critical of peers who do well in school," "needs to be reprimanded or sent to the office," and "is verbally or physically abusive to the teacher."

Initiative-taking behavior. Teachers reported on youth behavior with a 4-item 5 -point response $(1=$ never, $5=$ always) (Finn Initiative Scale, Finn et al., 1995; 8th grade revision, J. Finn, personal communication, October 14, 1998) scale each semester, $\alpha=.75, .82, .82$, and .85, respectively. Beginning with the stem "How often does this student ...," items were "do more than the work assigned?," "persist when confronted with difficult problems?," "actively participate in class discussions?," and "engage me in conversation about subject matter before or after school or outside of class?"

Absences. Eighth grade youth reported "How often are you absent from school or miss a class during the day?" on a 7-point scale $(1=$ never, $2=$ once or twice a year, $3=$ less than once a month, $4=$ once $a$ month or so, $5=$ once every few weeks, $6=$ once a week or so, $7=$ more than once a week), fall $M=3.17, S D=1.67$; spring $M=3.82, S D=1.79$. As a second measure of absences, a count of unexcused absences was obtained from school records in 8th and 9th grades (log transformed to reduce skew). Each day not enrolled in any school was counted as an absence.

\section{Academic Outcomes}

GPA. School record of core (math, history, science, English) grades $(0.0=F$ to $4.0=A)$ was obtained; 0.0 was assigned as GPA for students not enrolled in any school during the semester. As a baseline measure of grades prior to the intervention, we obtained youth report of prior grades.

Three additional academic outcome measures were obtained at the end of 8th grade: (a) proportion of subject tests passed on the 8th grade Essential Skills Attainment Test (based on the Michigan Educational Assessment Program (MEAP) test), $M=.80, S D=.25$, range $=0.0$ to 1.0 ), (b) referral to remedial summer school as a prerequisite to high school promotion (47\% of youth), and (c) retained in 8th grade according to school records by the end of the summer ( $9.5 \%$ of students). These measures were not available in 9th grade (standardized tests are not administered each year); therefore, 9th grade academic outcomes analyses focus on GPA only.

\section{Depression}

Youth report of depression, the standard 20-item, 4-point Center for Epidemiological Studies Depression Scale (Radloff, 1977), anchored at $0=$ not at all or less than one day in the past week and $3=5$ to 7 days in the past week, was obtained spring of 9th grade $(M=11.35, S D=8.33)$. Items include affective (e.g., "I felt depressed") and somatic (e.g., "I did not feel like eating; my appetite was poor") aspects of depression. Propor- tion of youth meeting the clinical threshold for depression (sum scores of at least 16) (Radloff \& Locke, 2000) was $22.7 \%$, comparable with the proportion of youth reaching the threshold for depression in national surveys (Costello, Mustillo, \& Erkanli, 2003; Roberts, Attkisson, \& Rosenblatt, 1998).

\section{Results}

We first examined the direct effect of the STJ intervention on PSs, self-regulatory behaviors, academic outcomes, and depression. Then, we examined PSs as mediators of intervention effects on self-regulatory behaviors and, via their impact on selfregulatory behavior, as mediators of intervention effects on academic outcomes and depression. We also examined whether the STJ intervention influenced the association between APSs and social identity. Prior to describing these analyses and results, we outline our decision to present analyses of both the "intention-totreat" (ITT) and compliant sample analyses.

\section{ITT and Compliant Sample Analyses}

Following standard procedure, direct effects analyses (Hypothesis 1) were conducted twice, once with the ITT sample and a second time with the compliant sample. Analyses of meditating effects of PSs (Hypothesis 2) and of the impact of the intervention on the relationship between APSs and social identity (Hypothesis 3) utilized the compliant sample. The ITT sample included all 264 youth randomized into experimental or control conditions, whether they were in school to receive the intervention or not.

Although analysis based on an ITT sample preserves random assignment, it is not a good test of the intervention effects to the extent that some people who did not receive the intervention are included in the treatment group for analyses. The alternative is to compare those who received a meaningful dose of the intervention with those who did not. This is termed compliance analyses. Use of compliance analyses to estimate effects for individuals who received a meaningful dose of an intervention is appropriate if assessed variables provide a useful and valid estimate of those likely to participate and if nonparticipators among those assigned to the experimental condition do not differ in outcomes from control condition youth (Jo, 2002a, 2002b). In the current study, both requirements were met, as outlined in more detail at http:// www.sitemaker.umich.edu/culture.self/files/ appendix_a_on_web_ site.doc, $26.0 \mathrm{~kb}$, the compliant sample $(n=228)$ included the "participating" youth $(n=116)$ and a comparable sample of control youth $(n=112)$. Participating youth were assigned to the experimental condition and received a reasonable dose of the intervention (i.e., attended at least five sessions). The comparable sample of control youth $(n=112)$ were youth who had a similar unobserved likelihood of "participating" had they been randomized to intervention according to the expectation maximization compliance model incorporating the full set of preintervention variables (Little \& Yau, 1998). Most of the difference in sample size between the ITT and compliant analyses was due to youth being suspended or expelled within the 1st month of school; some youth simply were not in school to receive the intervention. Effects presented are from the compliant (participating) sample unless otherwise specified. 
Hypothesis 1: STJ Intervention Has Direct Effects on PSs, Self-Regulatory Behavior, and Outcomes

\section{Analysis Plan}

We used multilevel modeling (MLM; Raudenbush \& Bryk, 2002; Snijders \& Bosker, 1999) to appropriately analyze variance at three levels - time nested within students and students nested within homerooms. We used standard methods for MLM, first building baseline models containing random effects for homeroom and time and then adding condition assignment and baseline control variables to optimize statistical power by accounting for preintervention variability in sex, race, age, baseline GPA (student report), baseline behavioral problems (teacher report), and baseline assessment of each dependent measure. For ease of interpretation, control variables (other than baseline assessment of the dependent variable) were constant across analyses. We show direct effects at the end of 8th grade and over time (through the end of 9th grade). For the longitudinal models predicting change in self-regulatory behavior and academic outcomes, we set the intercept for time at spring of 9th grade to obtain estimates of between-condition effects at the final measurement point. We used Raudenbush and Liu's $(2000,2001)$ methods to compute standardized effect sizes; these effects are calibrated to the residual level 1 variance of the unconditional model (i.e., the model containing no predictors other than homeroom) for 8th Grade MLM analyses and to the random slope and intercept variances of the unconditional model (i.e., the model with no predictors other than time and homeroom) for the longitudinal MLM. Standardized effect sizes are interpreted like Cohen's $d$.

\section{STJ Effects by End of 8th Grade}

Effects of STJ for the total ITT sample and the compliant (participating) sample are presented in Table 1. For each dependent variable, the raw coefficient is interpreted as a regression weight and indicates, in the metric of the dependent variable, the average within-homeroom difference between students assigned to STJ rather than the control group. The standardized effect size is interpreted as Cohen's $d$ and expresses the same difference in SD units. To further facilitate interpretation of intervention effects, estimated means for spring 8th grade are in the first columns of Table 2. We summarize findings by dependent variable in the sections below.

PSs. Following Hypothesis 1, both ITT and compliant sample analyses showed significant intervention effects on PSs in the spring of 8th grade. Experimental youth generated more balanced APSs, more plausible APSs, and more feared off-track PSs, setting the stage for self-regulation.

Self-regulatory behavior. As can be seen in the negative coefficients connoting fewer absences, participation in the STJ intervention significantly reduced absences, whether assessed via

Table 1

Multilevel Models: Effects of the STJ Intervention in Spring 8th Grade

\begin{tabular}{|c|c|c|c|c|c|}
\hline \multirow[b]{3}{*}{ Dependent variables } & \multirow{2}{*}{\multicolumn{2}{|c|}{$\begin{array}{l}\text { Total ITT sample } \\
\quad(N=264) \\
\text { Raw coefficients }\end{array}$}} & \multicolumn{3}{|c|}{$\begin{array}{l}\text { Participating sample }{ }^{\mathrm{a}} \\
\quad(N=228)\end{array}$} \\
\hline & & & \multicolumn{2}{|c|}{ Raw coefficients } & \multirow{2}{*}{$\begin{array}{l}\text { Standardized } \\
\text { effect size }^{\mathrm{b}}\end{array}$} \\
\hline & $B$ & $p$ & $B$ & $p$ & \\
\hline Change in APS balance & .157 & .023 & .186 & .014 & .269 \\
\hline Change in feared off-track PS & .286 & .004 & .308 & .003 & .302 \\
\hline APS plausibility & .340 & .015 & .400 & .008 & .329 \\
\hline Absences (student report) & -.417 & .043 & -.457 & .036 & -.267 \\
\hline Unexcused absences (school records) ${ }^{c}$ & -.183 & .049 & -.202 & .022 & -.726 \\
\hline Homework time (hrs/week; open ended) & .081 & .090 & .099 & .135 & .155 \\
\hline Homework time (hrs/week; closed ended) & .263 & .229 & .406 & .079 & .240 \\
\hline Disruptive behavior (student report) & -.307 & .165 & -.380 & .094 & -.209 \\
\hline Disruptive behavior (teacher report) & -.099 & .261 & -.139 & .149 & -.172 \\
\hline In-class initiative (teacher report) & .179 & .043 & .142 & .142 & .170 \\
\hline Core academic GPA (school records) & .229 & .021 & .218 & .039 & .252 \\
\hline Standardized tests (school records; proportion passed) & .068 & .017 & .086 & .006 & .360 \\
\hline Referral to remedial summer school ${ }^{\mathrm{d}}$ & -.194 & .457 & -.419 & .140 & \\
\hline Retention in 8th grade ${ }^{\mathrm{d}}$ & -.598 & .164 & -.979 & .076 & \\
\hline
\end{tabular}

Note. The cross-sectional multilevel models analyzed variance at two levels: students (Level 1), nested within homerooms (Level 2). All Level 1 intercepts were random, and all modeled fixed effects were at Level 1 (student). Models controlled for the following Level 1 (student) covariates: race, sex, baseline age, preintervention GPA (student-report), preintervention behavioral problems (teacher report), and preintervention assessment of the dependent variable, when available.

a The participating sample were 116 students who attended at least five in-school STJ sessions plus 112 students in the control group who had similar likelihood of attending, had they been randomly assigned to the intervention, according to maximum likelihood (EM) modeling of intervention compliance. ${ }^{\mathrm{b}}$ Interpretation is similar to $d$ for STJ intervention effects on individuals within homerooms. $\mathrm{ES}=\mathrm{B} / \mathrm{V}_{p}^{-1}$, where $\mathrm{B}=$ raw coefficient and $\mathrm{V}_{p}=$ residual variance in the unconditional intercept model, following Raudenbush \& Liu (2001). ${ }^{\mathrm{c}}$ These positively skewed dependent variables were log-transformed to reduce the influence of extreme scores. ${ }^{\mathrm{d}}$ Multilevel models for these dichotomous dependent variables used a logit link function. Standardized effect sizes could not be computed for logit models. 
Table 2

Multilevel Models: Estimated Means in Experimental and Control Conditions: Spring 8th and 9th Grades

\begin{tabular}{|c|c|c|c|c|}
\hline \multirow[b]{3}{*}{ Dependent variables } & \multicolumn{4}{|c|}{ Estimated condition means/percentages } \\
\hline & \multicolumn{2}{|c|}{ Spring of 8th grade } & \multicolumn{2}{|c|}{ Spring of 9th grade } \\
\hline & $\begin{array}{c}\text { STJ } \\
(n=116)\end{array}$ & $\begin{array}{c}\text { Control } \\
(n=112)\end{array}$ & $\begin{array}{c}\text { STJ } \\
(n=116)\end{array}$ & $\begin{array}{c}\text { Control } \\
(n=112)\end{array}$ \\
\hline Change in APS balance & 0.07 & -0.12 & & \\
\hline Change in feared off-track PS & 0.31 & 0.00 & & \\
\hline APS plausibility & 2.36 & 1.96 & & \\
\hline Absences (student report) & 3.49 & 3.95 & & \\
\hline Unexcused absences (school records) ${ }^{\mathrm{b}}$ & 12.28 & 14.53 & 22.52 & 24.77 \\
\hline Homework time (hours/week; open ended) ${ }^{\mathrm{b}}$ & 3.49 & 3.28 & 2.51 & 1.57 \\
\hline Homework time (hours/week; closed ended) & 4.15 & 3.74 & & \\
\hline Disruptive behavior (student report) & 2.37 & 2.63 & & \\
\hline Disruptive behavior (teacher report) & 1.74 & 1.83 & 1.55 & 1.73 \\
\hline In-class initiative (teacher report) & 2.51 & 2.44 & 2.48 & 2.25 \\
\hline Core academic GPA (school records) & 1.98 & 1.83 & 1.64 & 1.36 \\
\hline Standardized tests (school records; proportion passed) & 0.83 & 0.77 & & \\
\hline Referral to remedial summer school & $36.2 \%$ & $48.2 \%$ & & \\
\hline Retention in 8 th grade & $4.3 \%$ & $10.7 \%$ & & \\
\hline Depression $(\mathrm{CESD} \text { — spring of } 9 \text { th grade })^{\mathrm{c}}$ & & & 10.35 & 12.29 \\
\hline \multicolumn{5}{|c|}{$\begin{array}{l}\text { Note. } N=228 \text { youth in the participating sample. } \\
\text { a For variables with estimated means for both } 8 \text { th and } 9 \text { th grades, estimates were from the intercept term of a } \\
\text { three-level longitudinal multilevel model (time, students, homerooms); for variables with estimated means for } \\
\text { only one grade, estimates were from cross-sectional two level multilevel models (students in homerooms). } \\
\text { b These positively skewed variables were log transformed for analysis; however, to facilitate interpretation, } \\
\text { means are presented here in the original metric (i.e., in exponentiated form). }{ }^{\mathrm{c}} \text { Depression was measured only } \\
\text { in the spring of } 9 \text { th grade; means were estimated by a two-level cross-sectional multilevel model. }\end{array}$} \\
\hline
\end{tabular}

school or youth report, in both ITT and compliant samples. For school-reported absences, the effect of the intervention is in Cohen's large range, with $d$ near .80 . Each semester intervention youth attended more school, over 2 additional days, than control youth. With regard to time spent in homework and behavior in class, results are suggestive of STJ impact (for homework, student and teacher rated behavior, all $p<.15)$.

Academic outcomes. Intervention youth showed significantly better GPA and better standardized test scores using both ITT and compliance analyses. With regard to 8 th grade retention, more than twice as many control youths $(10.7 \%)$ as intervention youths $(4.3 \%)$ were retained, $p<.10)$.

\section{STJ Effects by End of 9th Grade}

Estimated means for the spring of 9th grade are in Table 2. Table 3 presents the direct effects of the STJ intervention on the trajectory of change over time and on the difference between intervention and control groups in the spring of 9th grade. For each dependent variable, the raw slope coefficient indicates the average within-homeroom difference in linear trajectory between students assigned to STJ and the control group. The raw intercept coefficient indicates the average spring 9th grade within-homeroom difference between students assigned to STJ and control group. Standardized effect sizes are interpreted as Cohen's $d$ and express the same differences in $S D$ units. The trajectories of change for each dependent variable are presented graphically in Figures 2 and 3.

Self-regulatory behavior. STJ youth spent significantly more time doing homework, were more likely to take initiative in class, less disruptive, and less likely to skip class than control group youth. As displayed in Figure 2a, time spent on homework declined for all youth, but the decline was significantly less for STJ youth. By spring of 9th grade, STJ youth were spending on average 2.51 hours a week on homework, nearly an hour more per week than control youth who averaged 1.57 hours per week. Both ITT and compliant sample analyses showed a large and significant effect of STJ on both level and trajectory of change over time in homework.

Trajectories of in-class behavior are displayed in Figure $2 b$ (initiative taking) and $2 \mathrm{c}$ (disruptive behavior). As can be seen, initiative-taking declined for control youth, not for STJ youth; disruptive behavior declined for all youth, but the decline was significantly steeper for STJ youth. Size of intervention effects is moderate for the trajectory of change in initiative-taking and large for the trajectory of change in disruption over time.

With regard to absences (skipping), as displayed in Figure 3a, the large and significant effect of the intervention at the end of 8th grade remained stable and significant through 9th grade. Each semester of 9th grade, STJ youth averaged 2.25 more days in school than control youth.

Academic outcomes. STJ and control youth differed significantly in GPA by the end of 9th grade, with the size of gap between groups increasing over time, as displayed graphically in Figure $3 b$; intervention effect sizes for both end of 9th grade level and trajectory over time were "small-to-moderate" using Cohen's (1988) rules of thumb. Within-time models comparing the STJ and control groups at each grading period showed that a significant 
Table 3

Longitudinal Multilevel Models: Effects of STJ Intervention on Change (Slope) and Level (Spring of 9th Grade) of Self-Regulatory Behavior, Academic Outcomes, and Depression

\begin{tabular}{|c|c|c|c|c|c|}
\hline \multirow[b]{3}{*}{ Dependent variables } & \multirow{2}{*}{\multicolumn{2}{|c|}{$\begin{array}{l}\text { Total ITT sample } \\
\qquad(N=264) \\
\text { Raw coefficients }\end{array}$}} & \multicolumn{3}{|c|}{$\begin{array}{l}\text { Participating sample }{ }^{\mathrm{a}} \\
\quad(N=228)\end{array}$} \\
\hline & & & \multicolumn{2}{|c|}{ Raw coefficients } & \multirow{2}{*}{$\begin{array}{l}\text { Standardized } \\
\text { effect size }^{\mathrm{b}}\end{array}$} \\
\hline & $B$ & $p$ & $B$ & $p$ & \\
\hline \multicolumn{6}{|l|}{ Homework time (open ended) ${ }^{\mathrm{c}}$} \\
\hline Spring 9th grade (intercept) & 0.166 & .043 & 0.183 & .035 & 0.742 \\
\hline Change trajectory (linear slope) & 0.011 & .050 & 0.012 & .041 & 1.044 \\
\hline \multicolumn{6}{|l|}{ Teacher-report of in-class initiative } \\
\hline Spring 9th grade (intercept) & 0.166 & .115 & 0.234 & .037 & 0.326 \\
\hline Change trajectory (linear slope) & 0.012 & .073 & 0.015 & .036 & 0.430 \\
\hline \multicolumn{6}{|l|}{ Teacher-report disruptive behavior } \\
\hline Spring 9th grade (intercept) & 0.085 & .283 & -0.178 & .030 & -0.326 \\
\hline Change trajectory (linear slope) & -0.005 & .366 & -0.010 & .040 & -0.776 \\
\hline \multicolumn{6}{|l|}{ School record of unexcused absences ${ }^{\mathrm{c}}$} \\
\hline Spring 9th grade (intercept) & -0.144 & .051 & -0.175 & .027 & -0.296 \\
\hline Change trajectory (linear slope) & 0.000 & .994 & 0.001 & .847 & 0.000 \\
\hline \multicolumn{6}{|l|}{ School record of core academic GPA } \\
\hline Spring 9th grade (intercept) & 0.211 & .074 & 0.277 & .031 & 0.300 \\
\hline Change trajectory (linear slope) & 0.164 & .266 & 0.030 & .055 & 0.354 \\
\hline \multicolumn{6}{|l|}{ Depression (CESD) $)^{\mathrm{d}}$} \\
\hline Spring 9th grade (intercept) & -1.355 & 187 & -1.943 & .049 & -0.257 \\
\hline
\end{tabular}

Note. The longitudinal multilevel models analyzed variance at three levels: time (Level 1) nested within students (Level 2), nested within homerooms (Level 3). All Level 2 intercepts and slopes were random. Models controlled for the following Level 2 (student) covariates: race, sex, baseline age, and preintervention GPA (student-report).

${ }^{\text {a }}$ The participating sample was 116 students who attended at least five in-school STJ sessions plus 112 students in the control group who had similar likelihood of attending, had they been randomly assigned to the intervention, according to maximum likelihood (EM) modeling of intervention compliance. ${ }^{\mathrm{b}}$ Interpretation is similar to $d$. For STJ intervention effects on the intercept, $\mathrm{ES}=\mathrm{B} / \mathrm{T}_{00}^{-1}$, where $\mathrm{B}=$ raw coefficient and $\mathrm{T}_{00}=$ intercept variance in the unconditional change model. For STJ effects on change in linear slopes, $\mathrm{ES}=\mathrm{B} / \mathrm{T}_{11}^{-1}$, where $\mathrm{B}=$ raw coefficient and $\mathrm{T}_{11}=$ variance of the individual linear change trajectories in the unconditional change model. For STJ effects on individuals within homerooms (for depression in spring of 9th grade), ES = $\mathrm{B} / \mathrm{V}_{p}^{-1}$, where $\mathrm{B}=$ raw coefficient and $\mathrm{V}_{p}=$ residual variance in the unconditional intercept model (Raudenbush \& Liu, 2001). ${ }^{\mathrm{c}}$ These positively skewed dependent variables were log-transformed to reduce the influence of extreme scores. ${ }^{\mathrm{d}}$ Depression was measured only in spring of 9th grade; coefficients are from a cross-sectional, two-level MLM.

difference in GPA emerged at the 3rd quarter, 2 quarters after the intervention $(B=.22, p<.02)$. GPA between groups continued to diverge over time. By the end of the 9th grade, estimated average GPA was 1.64 for STJ youth, compared with 1.36 for control group youth.

Depression. Intervention effects on depression were significant; estimated mean Center for Epidemiological Studies Depression Scale scores were nearly 2 points lower for STJ $(M=10.35)$ compared with control youth $(M=12.29)$ at the end of 9 th grade.

\section{Hypothesis 2: PSs Mediate STJ Effects on Self-Regulatory Behavior, Academic Outcomes, and Depression}

\section{Analysis Plan}

Having found support for hypothesis 1 (significant direct effects of STJ on PSs, self-regulatory behavior, academic outcomes, and depression) allowed for examination of hypothesis 2 (mediating effects of PSs). To test for mediation, we used latent structural equation modeling, employing standard methods to develop the measurement model defining the latent constructs, to assess overall model fit, and to calculate and test indirect effects. All SEM analyses used AMOS 5 software (Arbuckle \& Wothke, 2003).

Figure 4 displays the structural model of the hypothesized direct and indirect effects including four observed constructs (8th grade APS balance, APS plausibility, feared off-track PSs, and 9th Grade GPA) and four latent constructs (attendance, homework, classroom behavioral problems, and depression). The measurement model was developed to test associations between latent constructs and the observed indicators that measure them. As presented in Table 4, all loadings were above .46 (all $p<.01$ ). For the multiindicator latent constructs (all but depression), measurement error was reflected in the loadings linking observed indicators to latent constructs. For the single-indicator latent construct (the multiitem depression scale), measurement error was reflected by weighting the scale error variance by 1 - Cronbach's alpha for the depression scale $(1-.84=.16)$. Following standard practice, we allowed correlated errors among those indicator variables that shared measurement variance due to common source and item format. These were closed-ended student-report of attendance, homework, and classroom behavioral problems (error correlations 
A

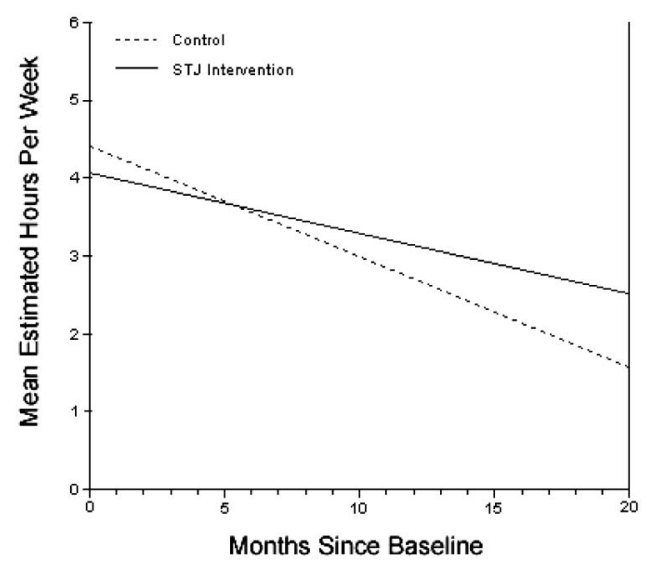

$\mathrm{B}$

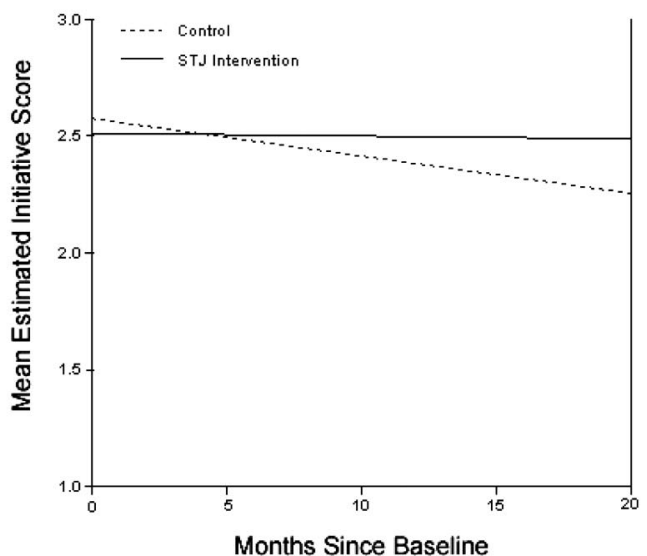

C

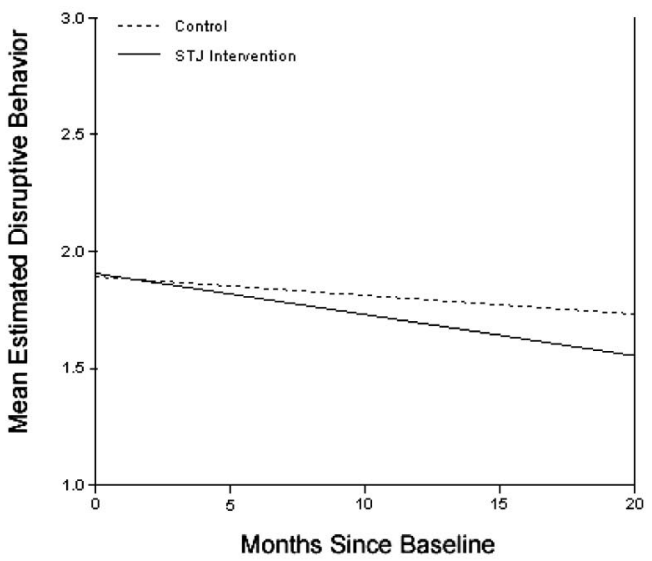

Note. Intervention occurred during months 1-2.

Figure 2. Effect of the STJ intervention over time on hours spent on homework each week (a), teacher-rated initiative (b), and teacher-rated disruptive behavior (c).

ranged from $r=.12$ to $r=.26$ ). Correlations among measurement errors of other indicators were fixed at zero.

The structural model of hypothesized direct and indirect effects was applied to the latent constructs defined in the measurement model. Single-headed arrows in Figure 4 indicate the directional conceptualization of the structural model: The influence of the intervention on PSs, self-regulatory behavior, academic outcomes, and depression. Associations among 8th grade measures of selfregulatory behavior (homework effort, classroom behavior problems, and absences) were specified as nondirectional correlations, indicated by curved, double-headed arrows. Multivariate normality of the full model was acceptable: Mardia's (1985) test of multivariate kurtosis $=10.57$, with univariate skew and kurtosis less than 1.2 for all endogenous variables. Fit of the full structural model to the data was assessed by $\chi^{2}$, supplemented by tests and critical thresholds recommended by $\mathrm{Hu}$ and Bentler (1999): standardized root mean residual $\leq .08$, root mean square error of approximation (RMSEA) $\leq .06$, and Bollen's incremental fit index $\geq .95$. With the sample size of 228 and $d f$ exceeding 100 , power exceeds .80 for a test of overall model fit using RMSEA (MacCallum, Browne, \& Sugawara, 1996). By current criteria, our sample size of 228 is adequate for stable and unbiased estimation of indirect effects and SEs (e.g., MacKinnon, Warsi, \& Dwyer, 1995). Bootstrapped, bias-corrected $S E$ s were used to test the significance of indirect effects (MacKinnon, Lockwood, Hoffman, West, \& Sheets, 2002; MacKinnon, Lockwood, \& Williams, 2004). Power to test the significance of mediated effects generally exceeded .80 given sample size, measure reliability, extent of collinearity between independent and mediating variables, and use of latent constructs (see Hoyle \& Kenny, 1999).

\section{Testing the Full Process Model}

The final structural model, shown in Figure 4, was an excellent fit to the data: $\chi^{2}(d f=146)=156.36, p=.26$; standardized root mean residual $=.05$, RMSEA $=.02$, incremental fit index $=.99$. 


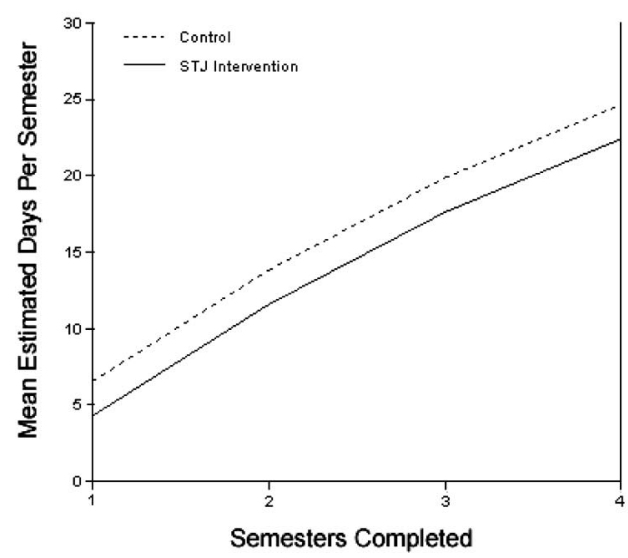

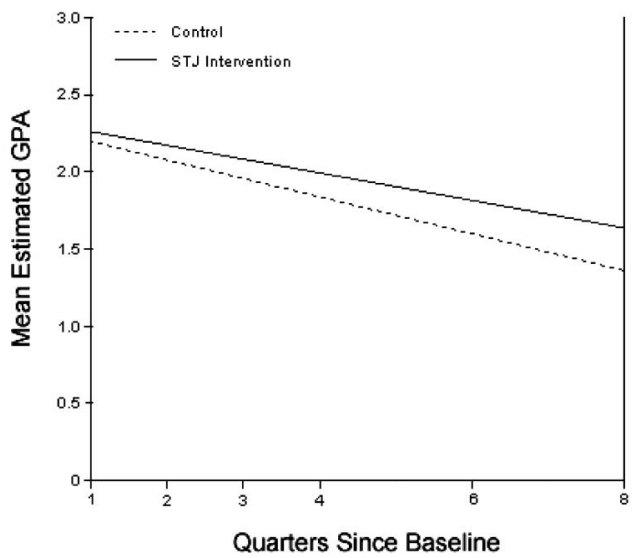

Note. Intervention occurred prior to the first point of measurement. GPA was obtained for each quarter of 8th grade and for each semester of 9th grade.

Figure 3. Effect of the STJ intervention on days absent per semester (a) and core academic grades (b).

The intervention had direct positive effects on PSs as well as a direct negative effect on school absences (reducing absences). Each PS variable had significant effects on 8th and 9th grade outcomes; all mediation paths were significant at $p<.05$. Nondirectional correlations among constructs were moderate and anticipated: 8th grade classroom behavioral problems were correlated positively with absences $(r=.50)$ and negatively with homework $(r=-.33)$. Table 5 lists the total and specific mediation paths linking the intervention with 8th and 9th grade effects.

\section{Interpreting the Mediating Effects of PSs}

APSs. The STJ intervention had positive direct effects on APSs (APS balance $B=.14$ and APS plausibility, $B=.12$ ), as well as an indirect effect on APS plausibility through APS balance (indirect $B=.02$ ). APS balance and APS plausibility were complete mediators of intervention effects on two of the self-regulatory behaviors in the 8 th grade-behavioral problems (indirect $B=$ -.02 ) and time spent in homework (indirect $B=.03$ ). On 9th

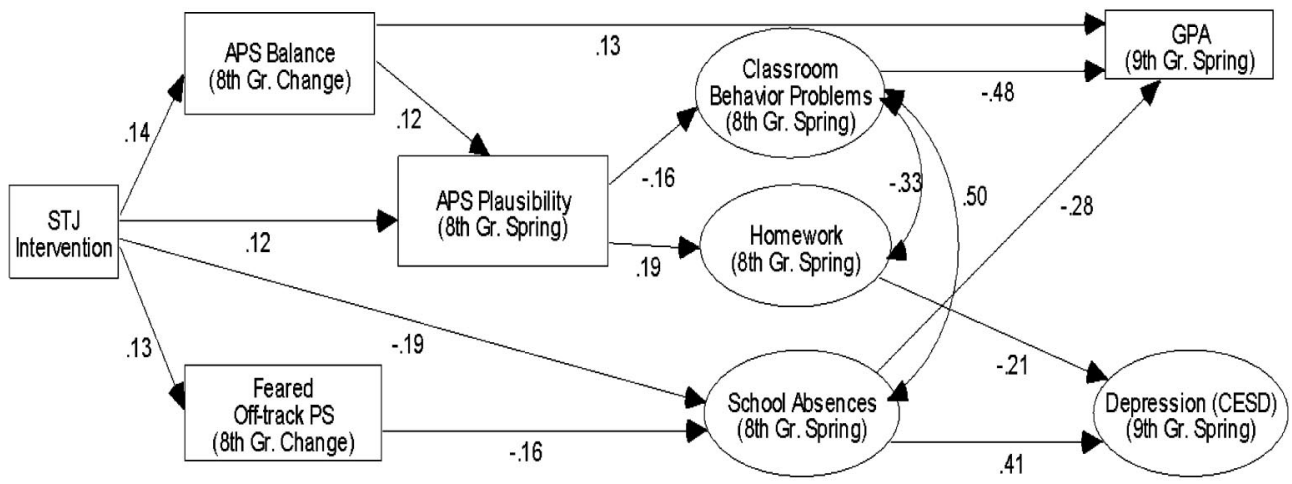

Note. Chi square $(d f=146)=156.36, p=.26 ;$ SRMR $=.05 ; \operatorname{RMSEA}=.02 ; \mathrm{IFI}=.99$.

Coefficients are standardized; all are significant at $p<.05$.

Model controls for the effects of sex, race, baseline GPA, fall 8th grade teacher report of classroom behavior problems, and fall 8 th grade PS.

$N=228$ youth ( 116 who attended at least 5 STJ sessions, plus 112 controls with similar likelihood of participating, had they been randomly assigned to receive the intervention, according to the EM compliance model).

Figure 4. Effects of the STJ intervention over time as mediated by PSs. 
Table 4

Measurement Coefficients for Latent Structural Equation Model

\begin{tabular}{lr}
\hline \multicolumn{1}{c}{ Latent constructs and observed indicators } & $\begin{array}{c}\text { Standardized } \\
\text { coefficient }\end{array}$ \\
\hline $\begin{array}{l}\text { Classroom behavior problems (8th grade) } \\
\text { Teacher report of disruptive behavior }\end{array}$ & \\
$\quad \begin{array}{l}\text { Student report of disruptive behavior } \\
\text { Teacher report of initiative }\end{array}$ & 0.817 \\
Homework (8th grade) & 0.465 \\
$\quad$ Closed-ended rating of time spent on homework each & \\
$\quad$ week & \\
$\quad$ Open-ended report of time spent on homework each & 0.468 \\
$\quad$ week & 0.888 \\
Absences (8th grade) & 0.764 \\
$\quad \begin{array}{l}\text { School record of unexcused absences } \\
\text { Student report of absences }\end{array}$ & 0.736 \\
Depression (9th grade) & 0.568 \\
$\quad$ CESD & 0.910 \\
\hline
\end{tabular}

Note. $N=228$ youth in the participating sample. All coefficients significant at $p<.001$.

${ }^{a}$ These indicators were set to 1 to define the scale of the construct.

${ }^{\mathrm{b}}$ Measurement error in this latent construct was modeled by weighting the error variance of the single indicator (the CESD scale score) by 1-Cronbach's alpha $(-.84=.16)$.

grade academic outcomes, APS balance and APS plausibility partially mediated intervention effects on GPA (indirect $B=.03$ ). APS balance and plausibility also partially mediated intervention effects on 9th grade depression (indirect $B=-.01$ ).

Feared off-track PSs. The intervention had positive direct effects on feared off-track PSs $(B=.13)$. Off-track PS was a partial mediator of intervention effects on 8th grade school ab- sences (indirect $B=-.02$ ). For 9th grade outcomes, off-track PS partially mediated intervention effects on academic outcomes GPA (indirect $B=.01$ ), as well as 9th grade depression (indirect $B=-.01)$.

\section{Hypothesis 3: STJ Influences the Relationship Between APS and Social Identity}

\section{Analysis Plan}

We used hierarchical multiple regression to examine the moderating effect of the STJ intervention on the Spring 9th Grade APS-social identity relationship. Fall 8th Grade APS was entered as a control variable at Block 1, experimental assignment at Block 2, Social Identity Connectedness at Block 3, and the Connectedness $\times$ Intervention interaction at Block 4. Methods recommended by Aiken and West (1991) were used to probe interaction effects and test significance of simple slopes.

\section{Effects on APS}

APS plausibility. The full model containing main effects and the STJ $\times$ Social Identity Connectedness interaction was significant, $F(4,223)=5.02, p<.001$, with added variance explained by the STJ $\times$ Social Identity Connectedness interaction, $B=.57$, $\Delta F(1,223)=3.78, p=.05$. For intervention youth, Connectedness and APS plausibility were positively associated, simple slope $B=.80, p<.001$, but for control youth, there was no significant relationship, simple slope $B=.22, p=.31$.

APS balance. The full model containing main effects and the STJ $\times$ Social Identity Connectedness interaction was marginally significant, $F(4,223)=1.95, p=.10$, and the STJ $\times$ Social

Table 5

Mediational Paths Linking the STJ Intervention to Spring 8th Grade and Spring 9th Grade Effects

\begin{tabular}{|c|c|c|}
\hline General and specific mediational paths & $\begin{array}{c}\text { Standardized } \\
\text { effect }\end{array}$ & $p$ \\
\hline \multicolumn{3}{|l|}{ STJ effects on spring 8th grade outcomes } \\
\hline Total STJ effect on classroom behavior problems (8th grade) & -0.022 & 0.023 \\
\hline STJ $\rightarrow$ APS balance $\rightarrow$ APS plausibility $\rightarrow$ classroom behavior problems & -0.003 & 0.034 \\
\hline STJ $\rightarrow$ APS plausibility $\rightarrow$ classroom behavior problems & -0.019 & 0.044 \\
\hline Total STJ effect on homework (8th grade) & 0.026 & 0.015 \\
\hline STJ $\rightarrow$ APS balance $\rightarrow$ APS plausibility $\rightarrow$ homework & 0.003 & 0.036 \\
\hline STJ $\rightarrow$ APS plausibility $\rightarrow$ homework & 0.023 & 0.025 \\
\hline Total STJ effect on absences (8th grade) & -0.208 & 0.002 \\
\hline STJ $\rightarrow$ feared off-track PS $\rightarrow$ absences & -0.021 & 0.027 \\
\hline $\mathrm{STJ} \rightarrow$ absences & -0.186 & 0.003 \\
\hline \multicolumn{3}{|l|}{ STJ effects on spring 9th grade outcomes } \\
\hline Total STJ effect on GPA (spring 9th grade) & 0.090 & 0.002 \\
\hline $\mathrm{STJ} \rightarrow$ APS balance $\rightarrow$ GPA & 0.019 & 0.018 \\
\hline STJ $\rightarrow$ APS balance $\rightarrow$ APS plausibility $\rightarrow$ classroom behavior $\rightarrow$ GPA & 0.002 & 0.028 \\
\hline STJ $\rightarrow$ APS plausibility $\rightarrow$ classroom behavior problems $\rightarrow$ GPA & 0.009 & 0.024 \\
\hline STJ $\rightarrow$ absences $\rightarrow$ GPA & 0.054 & 0.006 \\
\hline STJ $\rightarrow$ feared off-track PS $\rightarrow$ absences $\rightarrow$ GPA & 0.006 & 0.024 \\
\hline Total STJ effect on depression (spring 9th grade) & -0.091 & 0.001 \\
\hline STJ $\rightarrow$ APS balance $\rightarrow$ APS plausibility $\rightarrow$ homework $\rightarrow$ depression & -0.001 & 0.023 \\
\hline STJ $\rightarrow$ APS plausibility $\rightarrow$ homework $\rightarrow$ depression & -0.005 & 0.014 \\
\hline STJ $\rightarrow$ feared off-track PS $\rightarrow$ absences $\rightarrow$ depression & -0.009 & 0.017 \\
\hline STJ $\rightarrow$ absences $\rightarrow$ depression & -0.076 & 0.008 \\
\hline
\end{tabular}

Note. $\quad N=228$ youth in the participating sample. Italicized entries are for general indirect effects; nonitalicized entries are for specific indirect effect paths. 
Identity Connectedness interaction, $B=.21, \Delta F(1,223)=6.39$, $p=.01$, added significantly to variance explained. For intervention youth, Connectedness and APS balance were positively associated, simple slope $B=.13, p<.03$, but for control youth, there was no significant relationship, simple slope $B=-.08, p=.20$.

\section{Discussion}

Although PSs focused on school success are common, so is failure in school. We asked why PSs fail to produce sustained self-regulation, outlining a process model in which self-regulation and, therefore behavior change, is likely when PSs are linked with contextually salient strategies, when they are congruent with social identity, and when difficulty is understood as a normative part of the process of attaining PSs. Focusing explicitly on low-income and minority youth, we developed an intervention to link PSs and strategies, to incorporate difficulty as a normative part of pursuing PSs, and to facilitate a positive link between APSs and important social identities. Our basic premises were that self-concept is not monolithic, that PSs are differentially accessible, and that they are likely to influence behaviors only when linked to strategies, when experienced as compatible with social identity, and when difficulty working toward the PS is viewed as normative.

To ensure that the intervention effects would be sustained over time, the intervention occurred in school, with peers, during the school day and targeted each aspect of our process model. Structured group activities evoked academically focused PSs, made clear that APSs were held by peers (and therefore something that "we" aspire to), and highlighted the normativeness of difficulties and failures along the way to attaining PS goals. Thus, the intervention operationalized our theory of how PSs might influence self-regulatory behaviors (and through these behaviors, academic outcomes and well-being).

Although attaining and sustaining an intervention effect is notoriously difficult, we documented effects that were stable and even increasing over time. This sustained effect over 2 years is particularly impressive, given that the high-poverty neighborhoods the youth were embedded in and the difficulty of improving academic outcomes when prior academic attainment accounts for much of the variance to be explained. We were able to directly assess each aspect of the process model except the positive selfregulatory consequences of changing metacognitive experience. Moreover, we documented effects using two very different analytic strategies (structural equation modeling and longitudinal MLM) with different strengths and assumptions.

Structural equation modeling provided explicit test of hypothesized mediation paths via PSs to self-regulatory behavior to behavioral outcomes, using multiple sources of information to account for measurement error. MLM, by allowing us to look directly at intervention effects on trajectories of individual change as well as at specific points, provided an explicit test of the hypothesized effects over time. MLM documented that intervention effects on self-regulatory behavior (attendance, homework time, and behavior problems) and academic outcomes were stable or increased over our 2-year follow-up, while accounting for the nesting of students within homerooms.

Our focus on PSs of low-income and minority youths and their fit with social identity as working class, African American, or Latino was intentional. We chose PSs and social identity because these social identities are often assumed to be at odds with academic self-goals (Steinitz \& Solomon, 1986), and school failure has important consequences, increasing risk of depression and delinquency (Joseph, 1996; Kasen, Cohen, \& Brook, 1998), future unemployment, problems in parenting, and mental health problems (e.g., Stoep, Weiss, Kuo, Cheney, \& Cohen, 2003) and making successful completion of other developmental tasks less likely (Sandler \& Chassin, 2002). Low SES is a clear risk factor for school failure (Blair, Blair, \& Madamba, 1999; Orfield et al., 2004); the combination of minority race/ethnicity and low social class together account for about $19 \%$ of variance in academic attainment (McDermott, 1995). Improving outcomes in this highrisk group is both critical and difficult given that poverty and minority status are "fixed-risk" factors, unlikely to change dramatically over the student's middle and high school years.

As a test of our model, we chose to intervene in the fall of the final year of middle school. We chose this point both because the transition from middle to high school is associated with increased salience of important social class and racial ethnic social identities and because school failure rates begin to rise dramatically from the 1st year of high school (e.g., Seidman, LaRue, Aber, Lawrence, \& Feinman, 1994). The transition to high school is stressing, as can be seen in the outcomes for control group youth; without the intervention, self-regulatory behavior declines, academic outcomes erode, and risk of depression is higher. An intervention that bolsters APSs and behavioral engagement will improve outcomes in the last year of middle school, making the transition to high school less risky. In addition, middle schools are on average smaller and more homogeneous than high schools, making intervention focused on linking PSs and social identity simpler.

Youth who are not equipped with specific PSs that make engagement in school (attending, putting effort into homework, engaging teachers) a necessity are more likely to fall behind in high school simply because high schools are more impersonal and less likely to routinely fulfill their educational needs. Indeed, the transition to high school has been described as a consciousnessraising experience due to the influx of students of diverse racialethnic and economic backgrounds (Seidman, Aber, Allen, \& French, 1996). Ethnographic accounts suggest that low-SES teens do not realize that they are poor in homogeneously low-SES schools and neighborhoods where they appear average (Roderick, 2003; Steinitz \& Solomon, 1986). Low-SES students report learning that they are part of a low-SES group when they enter high school., making the transition to high school very stressing for these youth. Not surprisingly, racial-ethnic identity also becomes more salient in the transition (Altschul, Oyserman, \& Bybee, in press). Not only does the transition to high school raise consciousness of social identities and their relative standing, it also highlights ambiguities about the one's probable future. Schools no longer provide vocational or technical training, so youths not in advanced classes are in "general studies," implying that the point of school is either college or marking time. For all of these reasons, transition to high school is characterized by dropping grades and school involvement for low-SES and minority children (Seidman et al., 1994).

We documented that our intervention does change PSs, increasing both feared off-track and academically focused PSs and strategies to attain them. As hypothesized, intervention youth both had more of these PSs and were better able to use them to improve 
behavioral self-regulation. The intervention produced measurable change in PSs, and change in PSs predicted change in behavioral self-regulation-going to school rather than skipping, behaving and participating in class, and spending time on homework; selfregulation not only improved academic outcomes but, equally importantly, reduced risk of depression.

The impact of academically focused PSs on self-regulatory behaviors was distinct from the impact of feared off-track PSs on self-regulatory behaviors. Youth with balanced and plausible academically focused PSs spent more time doing homework, were less disruptive, and more behaviorally engaged in class-room activities. Youth with feared off-track PSs attended school more (had fewer school absences). The distinct role of feared off-track PSs is congruent with a number of self-regulatory models: Carver (2004) describes self-regulation to avoid feared PSs or antigoals as discrepancy-enlarging self-regulation. Larsen (2004) describes the self-regulatory system as vigilant to environmental dangers; when danger is cued, individuals are more cautious about engaging in behaviors that may increase risk. Higgins (Higgins \& Spiegel, 2004) describes prevention-focused self-regulation as risk averse. Following these perspectives, youth with feared off-track PSs can be expected to be cautious about risk-increasing behaviors and likely to engage in action (e.g., attending school) they perceive as antithetical to their off-track selves of becoming pregnant, involved in drugs, crime, or the police. Indeed, increased feared off-track PSs reduced risk of school absences. Although vigilant focus on antigoals or prevention is likely to reduce risk of harm, active engagement in goal attainment (discrepancy-reducing selfregulation) is likely to increase chances of success.

Although self-regulatory systems theories posit roles for both discrepancy-reducing (promotion) and discrepancy-increasing (prevention) systems, prevention focus, engaging in selfregulatory behavior to avoid feared PSs, is not particularly prominent in the academic goal literature. Perhaps this is because in middle-class contexts, pursuit of academic goals may more commonly involve the discrepancy reducing feedback system-engaging in self-regulatory behavior to attain positive expected PSs. There is evidence that college students are more likely to use promotion- than prevention-focused self-regulation (e.g., Lockwood, Sadler, Fyman, \& Tuck, 2004). However, prevention focused self-regulation may become more salient in a number of circumstances. First, prevention focused self-regulation may be more likely when social contextual risk is high, such as in circumstances of poverty. For example, first generation college students are more likely to engaging in strategies to avoid feared PSs than strategies to attain positive PSs (Oyserman, Gant, \& Ager, 1995, Study 1). Ethnographic evidence from low-income high school students also highlights the salience of feared off-track PSsbecoming unemployed, homeless, and destitute (Steinitz \& Solomon, 1986; see also Kaiser Foundation, 2002). Second, it is possible that culture influences choice of self-regulatory system; Euro-Canadian college students find promotion-focused strategies compelling, whereas Asian Canadian college students find prevention-focused strategies compelling (Lockwood, Marshall, \& Sadler, 2005). Similarly, Hong Kong Chinese college students found prevention-focused reasons for action more convincing than did American college students (Lee, Aaker, \& Gardner, 2000, Study 4).
Whether focused on positive expected or feared PSs, selfregulation fails when individuals do not realize that a particular action is antithetical to goal achievement, when PSs do not provide clear standards of what to attain or avoid, or when PSs are not linked with self-regulatory behaviors (e.g., Carver, 2004; Higgins, 1987). For low-income teens, lapses in self-regulation may be difficult to repair — when risk of failure is high, any misstep can spell disaster. This contrasts with the situation of middle-class teens whose self-regulatory lapses can be compensated for by contextual regulation set in place by neighborhood, school, and parents. Middle-class students are more likely to be provided mentoring, tutoring, monitoring, and enrichment activities whether they seek them out or not (e.g., Sampson, Morenoff, \& Earls, 1999). Low-income students are more likely to live in contexts lacking such collective efficacy resources (Sampson et al., 1999). Thus, for low-income youths, self-initiated engagement in selfregulation that focuses on attaining positive PSs and avoiding negative PSs is likely necessary.

Our emphasis on the situation of low-income and minority youth is congruent with research using the stereotype threat model (Steele, 1997) that demonstrates the undermining effect on academic outcomes of making stigmatized in-group social identity salient. To date, stereotype threat research has not documented the mechanism by which stereotype threat produces negative consequences over time. Our results suggest that stereotype threat may undermine academic attainment by making APSs less salient and school-focused strategies less accessible as ways of avoiding offtrack PSs. This process model is congruent with a number of studies documenting that when stereotype threat is activated, prevention (discrepancy enhancing) focus increases (Oyserman, Uskul, Yoder, Nesse, \& Williams, 2005; Seibt \& Förster, 2004), as do negative thoughts about one's math capacity (Cadinu, Maass, Rosabianca, \& Kiesner, 2005).

Our results demonstrate the real-world power of a social psychological conceptualization of the self as a motivational resource. By integrating PSs, social identity and metacognitive perspectives, we developed a process model that, when operationalized, produced lasting change on PSs, self-regulation, academic outcomes, and depression. These results are particularly promising given the difficulty in producing sustained improvement in the educational outcomes of low-income youths and the great need to develop integrative social science models that can be applied to ameliorating this large-scale social problem.

\section{References}

Abrams, D. (1994). Social self-regulation. Personality and Social Psychology Bulletin, 20, 473-483.

Aiken, L., \& West, S. (1991). Multiple regression: Testing and interpreting interactions. Newbury Park, CA: Sage.

Altschul, I., Oyserman, D., \& Bybee, D. (in press). Racial-ethnic identity in mid-adolescence: Content and change as predictors of academic attainment. Child Development.

Ambady, N., Paik, S., Steele, J., Owen-Smith, A., \& Mitchell, J. (2004). Deflecting negative self-relevant stereotype activation: The effects of individuation. Journal of Experimental Social Psychology, 40, 401-408.

Arbuckle, J., \& Wothke, W. (2003). AMOS 5.0 user's guide. Chicago: SmallWaters.

Arroyo, C., \& Zigler, E. (1995). Racial identity, academic achievement, and the psychological well-being of economically disadvantaged adolescents. Journal of Personality and Social Psychology, 69, 903-914. 
Baumeister, R. (1998). The self. In D. Gilbert, S. Fiske, \& G. Lindzey (Eds.), Handbook of social psychology (4th ed., pp. 680-740). New York: McGraw-Hill.

Belli, R. (1998). The structure of autobiographical memory and the event history calendar: Potential improvements in the quality of retrospective reports in surveys, Memory, 6, 383-406.

Blair, S., Blair, M., \& Madamba, A. (1999). Racial/ethnic differences in high school students' academic performance: Understanding the interweave of social class and ethnicity in the family context. Journal of Comparative Family Studies, 30, 539-555.

Burke, P. (2003). Relationships among multiple identities. In P. Burke \& T. Owens (Eds.), Advances in identity theory and research (pp. 195214). New York: Kluwer Academic/Plenum Press.

Cadinu, M., Maass, A., Rosabianca, A., \& Kiesner, J. (2005). Why do women underperform under stereotype threat? Evidence for the role of negative thinking. Psychological Science, 16, 572-578.

Carver, C. (2004). Self-regulation of action and affect. In R. Baumeister \& K. Vohs (Eds.), Handbook of self-regulation: Research, theory and applications (pp. 13-39). New York: Guilford Press.

Carver, C., \& Scheier, M. (1990). Principles of self-regulation: Action and emotion. In T. Higgins \& R. Sorrentinoeds (Eds.), Handbook of motivation and cognition (Vol. 2, pp. 3-52). New York: Guilford Press.

Cohen, J. (1988). Statistical power analysis for the behavioral sciences (2nd ed.). Hillsdale, NJ: Erlbaum.

Cook, P., \& Ludwig, J. (1997). Weighing the "burden of acting White": Are there race differences in attitudes toward education. Journal of Policy Analysis and Management, 16, 256-278.

Costello, E., Mustillo, S., \& Erkanli, A. (2003). Prevalence and development of psychiatric disorders in childhood and adolescence. Archives of General Psychiatry, 60, 837-844.

Cribbie, R., \& Jamieson, J. (2000). Structural equation models and the regression bias for measuring correlates of change. Educational and Psychological Measurement, 60, 893-907.

Croizet, J., \& Claire, T. (1998). Extending the concept of stereotype and threat to social class: The intellectual underperformance of students from low socioeconomic backgrounds. Personality and Social Psychology Bulletin, 24, 588-594.

Detroit News (2005, May 29). Graduation rates. Retrieved September 15, 2005, from http://www.detnews.com/2005/specialreport/0505/30/ A01-196697.htm

Eccles, J., \& Wigfield, A. (2002). Motivational beliefs, values, and goals. Annual Review of Psychology, 53, 109-132.

Ellickson, P., \& Hawes, J. (1989). An assessment of active versus passive methods for obtaining parental consent. Evaluation Review, 13, 45-55.

Ferguson, R. (1998). Comment on the burden of acting White: Do Black adolescents disparage academic achievement? by P. J. Cook and J. Ludwig. In C. Jencks \& M. Phillips (Eds.), The Black-White test score gap (pp. 394-397). Washington, DC: Brookings Institution.

Finn, J., Pannozzo, G., \& Voelkl, K. (1995). Disruptive and inattentivewithdrawn behavior and achievement among fourth graders. The Elementary School Journal, 95, 421-434.

Fordham, S., \& Ogbu, J. (1986). Black students' school success: Coping with the "burden of acting white." Urban Review, 18, 176-206.

Graham, S. (2001). Inferences about responsibility and values: Implication for academic motivation. In F. Salili, \& C. Chiu (Eds.), Student motivation: The culture and context of learning (pp. 31-59). Dordrecht, Netherlands: Kluwer Academic.

Higgins, T. (1987). Self-discrepancy: A theory relating self and affect. Psychological Review, 94, 319-340.

Higgins, T. (1996a). The "self digest": Self-knowledge serving selfregulatory functions. Journal of Personality and Social Psychology, 71, 1062-1083.

Higgins, T. (1996b). Knowledge activation: Accessibility, applicability, and salience. In T. Higgins \& A. Kruglanski (Eds.), Social psychology, handbook of basic principles (pp. 133-168). New York: Guilford Press.

Higgins, T. (1997). Beyond pleasure and pain. American Psychologist, 52, $1280-1300$

Higgins, T. (1998). The aboutness principle: A pervasive influence on human inference. Social Cognition, 16, 173-198.

Higgins, T., \& Spiegel, S. (2004). Promotion and prevention strategies for self-regulation: A motivated cognition perspective. In R. Baumeister \& K. Vohs (Eds.), Handbook of self-regulation: Research, theory and applications (pp. 171-187). New York: Guilford Press.

Hoyle, R., \& Kenny, D. (1999). Sample size, reliability, and tests of statistical mediation. In R. Hoyle (Ed.), Statistical strategies for small sample research (pp. 195-222). Thousand Oaks, CA: Sage.

Hu, L., \& Bentler, P. (1999). Cutoff criteria for fit indexes in covariance structure analysis: Conventional criteria versus new alternatives. Structural Equation Modeling, 6, 1-55.

James, W. (1890). Principles of psychology. New York: Holt.

Jo, B. (2002a). Estimation of intervention effects with noncompliance: Alternative model specifications. Journal of Educational and Behavioral Statistics, 27, 385-409.

Jo, B. (2002b). Model misspecification sensitivity analysis in estimating causal effects of interventions with noncompliance. Statistics in Medicine, 25, 305-327.

Joseph, J. (1996). School factors and delinquency: A study of African American youths. Journal of Black Studies, 26, 340-355.

Juster, T., Ono, H., \& Stafford, F. (2004). Changing times of American youth, 1981-2003. Retrieved September 14, 2005, from the University of Michigan Institute for Social Research Child Development Supplement to the Panel Study for Income Dynamics: http://www.umich.edu/ news/Releases/2004/Nov04/teen_time_report.pdf

Kaiser Foundation (2002). National Survey of Latinos. Summary of findings. Retrieved September 14, 2005, from http://www.kff.org/ kaiserpolls/20021217a-index.cfm

Kao, G. (2000). Group images and possible selves among adolescents: Linking stereotypes to expectations by race and ethnicity. Sociological Forum, 15, 407-430.

Kasen, S., Cohen, P., \& Brook, J. (1998). Adolescent school experiences and dropout, adolescent pregnancy, and young adult deviant behavior. Journal of Adolescent Research, 13, 49-72.

Kearney, K., Hopkins, R., Mauss, A., \& Weisheit, R. (1983). Sample bias resulting from a requirement for written parental consent. Public Opinion Quarterly, 47, 96-102.

King, L. (2001). The health benefits of writing about life goals. Personality and Social Psychology Bulletin, 27, 798-807.

King, L., \& Smith, N. (2004). Gay and straight possible selves: Goals, identity, subjective well-being, and personality development. Journal of Personality, 72, 967-994.

Larsen, R. (2004, November). Emotion and cognition: The case of automatic vigilance. APA online. Retrieved September 14, 2005, from http:// www.apa.org/science/psa/sb-larsen.html

Lee, A., Aaker, J., \& Gardner, W. (2000). The pleasures and pains of distinct self-construals: The role of interdependence in regulatory focus. Journal of Personality and Social Psychology, 78, 1122-1134.

Little, R., \& Rubin, D. (2002). Statistical analysis with missing data (2nd ed). New York: Wiley.

Little, R., \& Yau, L. (1998). Statistical techniques for analyzing data from prevention trials: Treatment of no-shows using Rubin's causal model. Psychological Methods, 3, 147-159.

Lockwood, P., Marshall, T., \& Sadler, P. (2005). Promoting success or preventing failure: Cultural differences in motivation by positive and negative role models. Personality and Social Psychology Bulletin 31, 379-392.

Lockwood, P., Sadler, P., Fyman, K., \& Tuck, S. (2004). To do or not to 
do: Using positive and negative role models to harness motivation. Social Cognition, 22, 422-450.

MacCallum, R., Browne, M., \& Sugawara, H. (1996). Power analysis and determination of sample size for covariance structure modeling. Psychological Methods, 1, 130-149.

MacKinnon, D., Lockwood, C., Hoffman, J., West, S., \& Sheets, V. (2002). A comparison of methods to test mediation and other intervening variable effects. Psychological Methods, 7, 83-104.

MacKinnon, D., Lockwood, C., \& Williams, J. (2004). Confidence limits for the indirect effect: Distribution of the product and resampling methods. Multivariate Behavioral Research, 39, 99-128.

MacKinnon, D., Warsi, G., \& Dwyer, J. (1995). A simulation study of mediated effect measures. Multivariate Behavioral Research, 30, 41-62.

Mardia, K. (1985). Mardia's test of multinormality. In S. Kotz \& N. Johnson (Eds.), Encyclopedia of statistical sciences (Vol. 5, pp. 217221). New York: Wiley.

Maris, E. (1998). Covariance adjustment versus gain scores: revisited. Psychological Methods, 3, 309-327.

McDermott, P. (1995). Sex, race, class, and other demographics as explanations for children's ability and adjustment: A national appraisal. Journal of School Psychology, 33, 75-91.

McGuire, W., \& Padawe-Singer, A. (1976). Trait salience in the spontaneous self-concept. Journal of Personality and Social Psychology, 33, $743-754$.

Orfield, G., Losen, D., Wald, J., \& Swanson, C. (2004). Losing our future: How minority youth are being left behind by the graduation rate crisis. Cambridge, MA: The Civil Rights Project at Harvard University. Retrieved September 14, 2005, from http://www.urban.org/UploadedPDF/ 410936_LosingOurFuture.pdf

Oyserman, D. (2001). Self-concept and identity. In A. Tesser \& N. Schwarz (Eds.), Blackwell handbook of social psychology (pp. 499517). Malden, MA: Blackwell Press.

Oyserman, D. (in press.) Social identity and self-regulation. In A. Kruglanski \& T. Higgins, Social psychology: Handbook of basic principles. New York: Guilford Press.

Oyserman, D., Bybee, D., Terry, K., \& Hart-Johnson, T. (2004). Possible selves as roadmaps. Journal of Research in Personality, 38, 130-149.

Oyserman, D., \& Fryberg, S. A. (2006). The possible selves of diverse adolescents: Content and function across gender, race, and national origin. In C. Dunkel \& J. Kerpelman (Eds.), Possible selves: Theory, research, and application (pp. 17-39). Huntington, NY: Nova.

Oyserman, D., Gant, L., \& Ager, J. (1995). A socially contextualized model of African American identity: Possible selves and school persistence. Journal of Personality and Social Psychology, 69, 1216-1232.

Oyserman, D., Johnson, E., \& Bybee, D. (2006). Effects of low socioeconomic status on early adolescent possible selves. Manuscript under editorial review.

Oyserman, D., \& Markus, H. (1990). Possible selves and delinquency. Journal of Personality and Social Psychology, 59, 112-125.

Oyserman, D., \& Saltz, E. (1993). Competence, delinquency, and attempts to attain possible selves. Journal of Personality and Social Psychology, 65, 360-374.

Oyserman, D., Terry, K., \& Bybee, D. (2002). A possible selves intervention to enhance school involvement. Journal of Adolescence, 24, 313326

Oyserman, D., Uskul, A., Yoder, N., Nesse, R., \& Williams, D. (2005). Unfair treatment and self-regulatory focus. Manuscript submitted for editorial review.

Pokorny, S., Jason, L., Schoeny, M., Townsend, S., \& Curie, C. (2001). Do participation rates change when active consent procedures replace passive consent. Evaluation Review, 25, 567-580.

Radloff, L. (1977). The CES-D scale: A self-report depression scale for research in the general population. Applied Psychological Measurement, 1, 385-401.
Radloff, L., \& Locke, B. (2000). Center for Epidemiologic Studies Depression Scale (CESD). In Taskforce for the Handbook of Psychiatric Measures (Eds.), Handbook of psychiatric measures: American Psychiatric Association (pp. 523-526). Washington, DC: American Psychiatric Association.

Raudenbush, S., \& Bryk, A. (2002). Hierarchical linear models: Applications and data analysis methods (2nd ed.). Thousand Oaks, CA: Sage.

Raudenbush, S., \& Liu, X. (2000). Statistical power and optimal design for multisite randomized trials. Psychological Methods, 5, 199-213.

Raudenbush, S., \& Liu, X. (2001). Effects of study duration, frequency of observation, and sample size on power in studies of group differences in polynomial change. Psychological Methods, 6, 387-401.

Régner, I., Huguet, P., \& Monteil, J. (2002). Effects of socioeconomic status (SES) information on cognitive ability inferences: When low-SES students make use of a self-threatening stereotype. Social Psychology of Education, 5, 253-269.

Roberts, R., Attkisson, C., \& Rosenblatt, A. (1998). Prevalence of psychopathology among children and adolescents. American Journal of Psychiatry, 155, 715-725.

Roderick, M. (2003). What's happening to the boys? Early high school experiences and school outcomes among African American male adolescents in Chicago. Urban Education, 38, 538-607.

Rothman, A., \& Schwarz, N. (1998). Constructing perceptions of vulnerability: Personal relevance and the use of experiential information in health judgments. Personality and Social Psychology Bulletin, 24, 1053-1064.

Ruvolo, A., \& Markus, H. (1992). Possible selves and performance: The power of self-relevant imagery. Social Cognition, 10, 95-124.

Sampson, R., Morenoff, J., \& Earls, F. (1999). Beyond social capital: Spatial dynamics of collective efficacy for children. American Sociological Review, 64, 633-660.

Sandler, I., \& Chassin, L. (2002). Training of prevention researchers: Perspectives from the Arizona State University Prevention Research Training Program. Prevention \& Treatment, 5, Item 5. Retrieved April 10, 2006, from http://journals.apa.org/prevention/volume5/pre0050006a.html

Schwarz, N. (1998). Accessible content and accessibility experiences: The interplay of declarative and experiential information in judgment. Personality and Social Psychology Review, 2, 87-99.

Schwarz, N. (2002). Situated cognition and the wisdom of feelings: Cognitive tuning. In L. Feldman Barrett \& P. Salovey (Eds.), The wisdom in feelings (pp. 144-166). New York: Guilford Press.

Schwarz, N., \& Bless, H. (1992). Constructing reality and its alternatives: An inclusion/exclusion model of assimilation and contrast effects in social judgment. In: L. Martin \& A. Tesser (Eds.), The construction of social judgments (pp. 217-245). Hillsdale, NJ: Erlbaum.

Schwarz, N., \& Clore, G. (1996). Feelings and phenomenal experiences. In: T. Higgins \& A. Kruglanski (Eds.), Social psychology: A handbook of basic principles. New York: Guilford Press.

Seibt, B., \& Förster, J. (2004). Stereotype threat and performance: How self-stereotypes influence processing by inducing regulatory foci. Journal of Personality and Social Psychology, 87, 38-56.

Seidman, E., Aber, J., Allen, L., \& French, S. (1996). The impact of the transition to high school on the self-esteem and perceived social context of poor urban youth. American Journal of Community Psychology, 24, $489-515$.

Seidman, E., Allen, L., Aber, J. L., Mitchell, C., \& Feinman, J. (1994). The impact of school transitions in early adolescence on the self-system and perceived social context of poor urban youth. Child Development, 65, $507-522$.

Settles, I. H. (2004). When multiple identities interfere: The role of identity centrality. Personality and Social Psychology Bulletin, 30, 487-500.

Snijders, T., \& Bosker, R. (1999). Multilevel analysis: An introduction to basic and advanced multilevel modeling. London: Sage. 
Steele, C. (1997). A threat in the air: How stereotypes shape intellectual identity and performance. American Psychologist, 52, 613-629.

Steinitz, V., \& Solomon, E. (1986). Starting out: Class and community in the lives of working-class youth. Philadelphia: Temple University Press.

Stoep, A., Weiss, N., Kuo, E., Cheney, D., \& Cohen, P. (2003). What proportion of failure to complete secondary school in the U.S. population is attributable to adolescent psychiatric disorder? Journal of Behavioral Health Services and Research, 30, 119-124.

Strauman, T. (2002). Self-regulation and depression. Self \& Identity, 1, $151-157$.

Strauman, T., \& Higgins, T. (1988). Self-discrepancies as predictors of vulnerability to distinct syndromes of chronic emotional distress. Journal of Personality, 56, 685-707.
Thomas, D., Townsend, T., \& Belgrave, F. (2003). The influence of cultural and racial identification on the psychosocial adjustment of inner-city African American children in school. American Journal of Community Psychology, 32, 217-228.

U.S. Bureau of the Census (2000). Census 2000. Retrieved April 10, 2006, from http://www.census.gov

Weinger, S. (2000). Opportunities for career success: Views of poor and middle-class children. Children \& Youth Services Review, 22, 13-35.

Weinstein, N. (1993). Testing four competing theories of health-protective behavior. Health Psychology, 12, 324-333.

Received December 22, 2004

Revision received January 4, 2006

Accepted January 24, 2006 